In this expression, the magnitudes indicated by the capital letters may belong to the solvent, those indicated by small letters to the substance dissolved. The vapor-tension $S$ would, of course, be that, not of the pure solvent but as diminished by the material in solution, according to Raoult's law.

In practice the method thus outlined may be carried out as follows: Assume, as a concrete case, that a determination of the tension of iodine in a solution of this element with potassium iodide and water is to be undertaken. The solution is weighed in a suitable vessel, and placed in a thermostat. A slow current of dry air is passed through it for a time, and it is again weighed. The loss of weight equals evaporated water plus iodine, (or $=w+W$ ), and titration of the solution before and after shows how much of this loss is due to evaporated iodine.

All the required data for formula (3) are therefore at hand. As yet, the method has been applied only to a study of starch iodide, of which an account will be found in the following paper. It was devised and experiments with it were begun more than two years ago, but circumstances beyond control of the present writer have delayed publication so long already that it seems undesirable to withhold preliminary notice any longer.

So far as iodine solutions are concerned, I would reserve the field for a time.

\title{
CONTRIBUTIONS TO THE STUDY OF STARCH IODIDE.
}

By LaUnCELOT W. AndRfís and HeNRy Max Goittsch.

Recelved June $;,$ 1002.

Since the discovery of the blue substance known as "starch iodide" by Stromeyer, " our knowledge of its properties has been enriched by numerous researches ${ }^{2}$. In spite, however, of the remarkably extensive literature pertaining to the subject, no consensus of opinion has been arrived at with regard to either the nature of the substance, its composition, or even some of its more important properties.

Thus, while Blondlot, Béchamp, Pohl, R. Fresenius, Duclaux, Brückner, and Küster ${ }^{2}$ consider it to be a mixture of starch with

1 Thorpe's Dict., vol. III, p. 565.

2 See bibliography at the end of this paper. 
iodine, or a solution of the latter in the former, Rouvier, Payen, Fritsche, Bondonneau, P. Guichard, Sonstadt, Pellet and others hold it to be a.chemical compound of starch and iodine. These authorities are nevertheless far from agreement as to the composition of the compound. They give the amount of iodine containerl all the way from 3.2 per cent. as a minimum, up to 19.6 per cent. as a maximum, and present formulas varying over a correspondingly wide range.

Ostwald, in the first edition of his "Wissenschaftliche Grundlagen," holds it to be an easily dissociable compound, while in the second edition of the same book, influenced probably by Küster's recent work, he adds the modifying clause "beziehungsweise einer festen Lösung." Bernthsen ${ }^{1}$ takes an identical view, ${ }^{2}$ regarding starch iodide as a dissociable compound.

Mylius ${ }^{3}$ maintains that the presence of hydriodic acid or an iodide is essential to the formation of starch iodide, to which he assigns the formula $\left(\mathrm{C}_{24} \mathrm{H}_{40} \mathrm{O}_{20} \mathrm{I}\right){ }_{4} \mathrm{HI}$ as most probable. Seyfert, as also Tóth, disputed the presence of hydriodic acid or alkali iodide as essential to the existence of the blue compound.

\section{EXPERIMENTAI.}

It seemed best to simplify the conditions so tar as possible by confining the study of the action of iodine on starch to clear solutions of the latter, in order to avoid complications arising from variations in the physical condition of the starch. Therefore, in the work described in the following pages, only such solutions were used.

The iodine employed was prepared from "chemically pure" iodine of the shops by distillation with potassium iodide in a current of steam. It was free from cyanide.

The solutions of starch were made by heating maize starch ${ }^{*}$ with water in an autoclave. At first a few drops of chloroform were added to the solutions as a preservative, but, as this seemed to induce partial precipitation of starch after standing, this practice was discarded after the first set of experiments described below.

1 "Organische Chemie," sixth edition, p. 307.

2 " Sowohl die Stärkekörner, als der Stärkekleister werden von Jod intensiv blau, von Brom feuergeib gefärbt, indem lockere, additionelle Verbindungen entstehen."

a See bibliography.

4 Washed with water, dilute hydrochloric acid, alcohol, and water. 


\section{Starch Iodide Prepared in the Cold.}

Series $I$.-Ten grams of starch were heated to $\mathrm{I} 75^{\circ}$ with $100 \mathrm{cc}$. of water for about three hours. The solution was brownish but perfectly clear, and filtered readily. A few drops of chloroform were added, and after standing a day, part of the starch had precipitated. The solution, somewhat diluted, was well shaken with fine asbestos, when it easily filtered clear.

To determine the strength of this solution, $5 \mathrm{cc}$. were evaporated to dryness at $100^{\circ}$ and brought to constant weight by heating in an air-bath at $105^{\circ}-110^{\circ}$. This operation demands care, in consequence of the extraordinarily hygroscopic character of the product. Five cc. of solution yielded 0.1834 gram of starch.

This standard solution was diluted to make solutions containing respectively, I0.000, 5.000, 2.500, I.250, and 0.625 grams per liter. To each solution was added an amount of pulverized iodine equal to the amount of starch present, and the whole was shaken by a motor (usually for about six hours), allowed to stand over night, a sample withdrawn for titration, and the remainder again shaken, etc. In the following table the amounts, in grams per liter, of iodine dissolved are shown.

Concentration of starch,

g. per L........ 10 $\quad 5^{1} \quad 5 \quad 2.5 \quad 1.25 \quad 0.625$

Concentration of iodine, g. per L :

$\begin{array}{llllllll}\text { After } 5 \text { days........ } & \ldots & 0.744 & 0.474 & 0.468 & 0.290 & 0.264 & 0.242\end{array}$

$\begin{array}{lllllll}\text { After } 7 \text { days.......... } 0.842 & 0.520 & 0.526 & 0.348 & 0.290 & 0.252\end{array}$

$\begin{array}{lllllll}\text { After IO days.......... } & 0.894 & 0.552 & 0.566 & 0.342 & 0.299 & 0.262\end{array}$

$\begin{array}{lllllll}\text { After II days........... } & 0.922 & 0.572 & 0.598 & 0.408 & 0.318 & 0.270\end{array}$

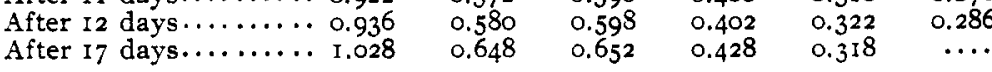

If the results are plotted as a curve with the respective starch concentrations as ordinates and the final iodine concentrations (solubilities) as abscissas, practically a straight line is obtained. This line cuts the $x$ axis at a point corresponding to the iodine concentration of 0.24 gram per liter, about, that is to say, at the point corresponding very closely with the best determinations of the solubility of iodine in water. The temperature fluctuated between $22^{\circ}$ and $25^{\circ}, 20^{\circ}$ being only once recorded.

1 This solution was freed from chloroform by blowing air through it before adding iodine. The figures show that the presence of traces of chloroform do not influence the solubility of the iodine. 
Allowing for the solubility of the iodine in the water, we find a fairly steady relation between iodine and starch. The mean value of this relation is about 7.63 per cent., or in other words, the "starch iodide" in the solution contains about 7 . I per cent. of iodine.

Since the starch solution used in this series of experiments gave some evidence of having been heated to too high a temperature (it gave with a trace of iodine a violet instead of clear blue), we determined upon another series, in which the solutions should be made at a lower temperature. It was found that the starch dissolved completely at $144^{\circ}$ but precipitated again on cooling, but at $152^{\circ}$ ( 5 atmospheres pressure) the solution remained clear long enough for the object in view.

Series 2.-Fifteen grams of starch were heated for two and a half hours to $152^{\circ}$ with I $30 \mathrm{cc}$. of water. The resulting colorless solution filtered readily and did not show any tendency to precipitate on cooling. It was diluted without delay to 6 so cc., of which $5 \mathrm{cc}$. were evaporated as before to determine the starch. 0.1077 gram of dry starch was obtained.

From this standard solution, six others were at once made, without waiting for the result of the determination, in order to avoid the possibility of separation of starch. These contained in $200 \mathrm{cc}$., respectively, 200, I 50, 100, 75, 50, and $25 \mathrm{cc}$. of standard solution, or, 21.54, I6.I6, I0.78, 8.08, 5.38, 2.70 grams of starch per liter.

These solutions were shaken six hours a day for ten days with excess of iodine at $21^{\circ}$ to $26^{\circ}$. They then contained no undissolved starch or starch iodide, and were filtered to remove any finely divided iodine in suspension, and titrated with $\mathrm{N} / \mathrm{IOO}$ sodium thiosulphate. The data so obtained are recorded in the following table.

\section{TABLE II.}

$C_{s}$. Concentration of starch, grams

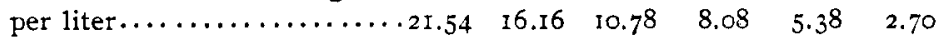

C. Concentration of iodine dis$\begin{array}{lllllll}\text { solved, grams per liter ....... I.644 } & \text { I.316 } & 0.970 & 0.786 & 0.602 & 0.446\end{array}$

$C-C$. Concentration of iodine $\begin{array}{lllllll}\text { corrected for solubility in water } & \text { I.376 } & 1.048 & 0.702 & 0.518 & 0.334 & 0.178\end{array}$

$P$. Ratio of starch to iodine in percentage $\ldots \ldots \ldots \ldots \ldots \ldots, 6.39$

$\begin{array}{lllll}6.48 & 6.51 & 6.4 I & 6.21 & 6.59\end{array}$


The data given in the table under rubrics I and II were reduced by the formula IOo $\frac{C-C_{w}}{C_{s}}=P$, in which

$C_{s}=$ the concentration of the starch (rubric I);

$C_{w}=$ the iodine dissolved in the water alone, assumed as constant ;

$C=$ total concentration of dissolved iodine (rubric II);

$P=$ per cent. of iodine taken up by the starch.

The numerical values of $C_{w}$ and of $P$ as calculated from the observations themselves are, respectively, 0.268 and 6.43 . The former is in excellent agreement with the known solubility of iodine in water. The temperature varied between $21^{\circ}$ and $26^{\circ}$. The percentage of iodine to starch found, 6.43 , corresponds fairly to that required by the formula $\left(\mathrm{C}_{6} \mathrm{H}_{10} \mathrm{O}_{3}\right)_{12} \mathrm{I}$, which is 6.53 .

Series 3.-The preceding experiments having established that the amount of iodine taken up by the starch is constant and independent of the concentration of the starch solution so long as the water is saturated by iodine, ${ }^{1}$ it was decided to make a series of determinations of the distribution of iodine between starch iodide solutions and an immiscible solvent (chloroform). ${ }^{2}$

The starch iodide solutions (being identical with those used in the experiments of Series 2) were shaken with Io per cent. (by volume) of carefully purified chloroform in stoppered glass cylinders, until a condition of equilibrium was attained, and were then allowed to stand for several hours, usually over night, to permit the liquids to separate completely. Five cc. of the clear supernatant blue solution were titrated with $\mathrm{N} / 200$ thiosulphate and the rest of it transferred to a dry cylinder and mixed as before with io per cent. of its volume of chloroform.

In this way, six successive distribution determinations were made on each solution with constant concentration as to starch but diminishing iodine. The temperatures did not vary more than $I^{\circ}$ from $2 \mathrm{I}^{\circ}$ throughout the series.

1 Kiister ( $A n n$. Chem. (Liebig), 360, 283) concludes that the amount of iodine absorbed by solid starch is wholly dependent on the concentration of the solution in contact: with it.

2 Compare Jakovkin's study of the dissociation of potassium triiodide in aqueous solution (Ztschr. phys. Chem., 13, 539 (1894)). 
870 LAUNCELOT W. ANDREWS AND HENRY MAX GOETTSCH.

TABLE III.

Distribution of Iodine betzeen Starch Solution and Chloroform.

\begin{tabular}{|c|c|c|c|c|c|}
\hline 1. & $\begin{array}{l}2 . \\
\text { A. }\end{array}$ & $\ddot{B}$. & 4 & $B \stackrel{5}{\div} A$. & $\begin{array}{c}6 . \\
B C \div-4\end{array}$ \\
\hline$\dot{E}$ & 45 & $\bar{c}$ & $\Xi$ & 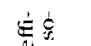 & 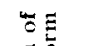 \\
\hline$\equiv$ & 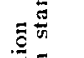 & 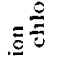 & & 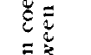 & 吾 \\
\hline 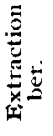 & 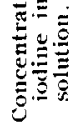 & 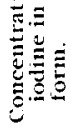 & 吾 & 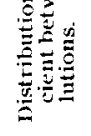 & 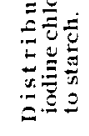 \\
\hline 0 & I. 644 & 0.00 & $2 \mathrm{I} .54$ & $\ldots$ & $\ldots$ \\
\hline I & I. 218 & 4.26 & 21.54 & 3.50 & \\
\hline 2 & 1.076 & 1.42 & 21.54 & 1.32 & $\begin{array}{l}75.5 \\
28.4\end{array}$ \\
\hline 3 & 0.990 & 0.86 & $2 I .54$ & 0.87 & 8.4 \\
\hline 4 & 0.918 & 0.72 & $2 I .54$ & $0.7^{9}$ & \\
\hline 5 & 0.890 & 0.28 & 21.54 & 0.31 & $\ldots$ \\
\hline 6 & $0.85^{8}$ & 0.32 & $2 \mathrm{I} .54$ & 0.37 & $\cdots$ \\
\hline o & I. 316 & 0.00 & I6, I 6 & $\ldots$ & \\
\hline I & 0.910 & 4.06 & I6. 16 & 4.46 & \\
\hline 2 & 0.780 & 1.30 & I6.16 & 1.67 & $72 . I$ \\
\hline 3 & 0.732 & 0.48 & I 6.16 & 0.66 & 27.0 \\
\hline 4 & 0.682 & 0.50 & I6.16 & 0.73 & 10.5 \\
\hline 5 & 0.644 & $0.3^{8}$ & I6. I 6 & 0.59 & .. \\
\hline 6 & 0.620 & 0.24 & 16.16 & 0.39 & $\ldots$ \\
\hline 0 & $0.97^{\circ}$ & 0.00 & 10.78 & $\ldots$ & $\ldots$ \\
\hline I & 0.616 & 3.54 & I0.78 & 5.74 & \\
\hline 2 & 0.524 & 0.92 & I0. 78 & I. $7^{6}$ & 61.6 \\
\hline 3 & 0.484 & 0.40 & I 0.78 & 0.83 & 19.0 \\
\hline 4 & 0.442 & 0.42 & 10.73 & 0.95 & 8.9 \\
\hline 5 & 0.408 & 0.34 & $10.7^{8}$ & $0.8_{3}$ & $\cdots$ \\
\hline 6 & 0.380 & 0.28 & $10.7^{8}$ & 0.74 & $\cdots$ \\
\hline 0 & 0.786 & 0.00 & 8.08 & $\ldots$ & $\ldots$ \\
\hline I & 0.472 & 3.14 & 8.08 & 6.65 & \\
\hline 2 & 0.394 & $0.7^{8}$ & 8.08 & I. 98 & 53.7 \\
\hline 3 & 0.348 & 0.46 & 8.08 & 1.32 & 16.0 \\
\hline 4 & 0.318 & 0.30 & 8.08 & 0.94 & 10.7 \\
\hline 5 & 0.290 & 0.28 & 8.08 & 0.97 & $\ldots$ \\
\hline 6 & 0.276 & 0.14 & 8.08 & $0.5^{\circ}$ & $\cdots$ \\
\hline 0 & 0.609 & 0.00 & $5 \cdot 38$ & $\ldots$ & $\ldots$ \\
\hline I & 0.328 & 2.74 & $5.3^{8}$ & 8.3 .5 & \\
\hline 2 & 0.250 & $0.7^{8}$ & $5 \cdot 38$ & 3.12 & 45.0 \\
\hline 3 & 0.250 & 0.40 & $5 \cdot 3^{8}$ & 1.90 & I 6.8 \\
\hline 4 & 0.190 & 0.20 & $5 \cdot 3^{S}$ & 1.05 & 10.2 \\
\hline 5 & 0.176 & 0.14 & $5 \cdot 3^{8}$ & 0.80 & $\cdot$ \\
\hline 6 & o. $15^{8}$ & 0.18 & $5 \cdot 3^{8}$ & I. I 4 & $\cdots$ \\
\hline
\end{tabular}




\begin{tabular}{|c|c|c|c|c|c|}
\hline I. & 2. & $\begin{array}{l}3 . \\
B \\
B\end{array}$ & 4. & $\stackrel{5}{-}$ & 6. \\
\hline 目 & 45 & og & 5 & 它 & . \\
\hline 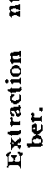 & 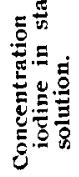 & 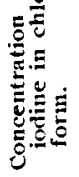 & 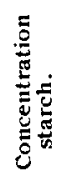 & 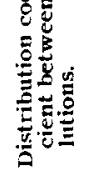 & 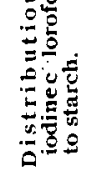 \\
\hline o & 0.446 & 0.00 & 2.70 & $\cdots$ & $\cdots$ \\
\hline I & o.176 & 2.70 & 2.70 & $15 \cdot 34$ & \\
\hline 2 & 0.122 & 0.54 & 2.70 & 4.42 & 41.5 \\
\hline 3 & 0.098 & 0.24 & 2.70 & 2.45 & II.9 \\
\hline 4 & 0.86 & 0.12 & 2.70 & 1.40 & 5.4 \\
\hline 5 & 0.72 & 0.14 & 2.70 & 1.94 & $\cdots$ \\
\hline 6 & 0.66 & 0.06 & 2.70 & 0.91 & $\ldots$ \\
\hline
\end{tabular}

All concentrations are given in grams per liter.

Inasmuch as the iodine in the chloroform was determined by difference, there is an accumulation of errors in the values found for the chloroform concentrations (column 3 ) for the last three extractions and in the corresponding distribution coefficients (column 5). It will be observed that there is no indication of a constant distribution coefficient between chloroform and starch solution or between chloroform and dissolved starch. The results show a more rapid removal of the iodine from the solutions containing less starch, in such a way that all the curves cross at nearly a common point, corresponding to about 5 per cent., falling between the first and second extractions.

Series 4. (Starch Iodide Prepared by Heating).-43.I52 grams of air-dried starch, containing 38.449 grams of dry starch (maize), were introduced into a Jena glass tube with 7 grams of pure iodine and enough water to moisten the mass completely. The tube was then sealed and heated to $99^{\circ}$ for two hours. At the end of this time the contents formed a soft mass which readily dissolved in water, leaving an insoluble residue consisting of the excess of iodine only, but containing no starch. The solution, diluted to 2 liters, was found on titration with $N / 100$ thiosulphate, to contain $2.562 \mathrm{mg}$. "free" iodine per cubic centimeter. From this standard solution were prepared, by appropriate dilution, five others, the strength of each of which, expressed in grams per liter and also in molecular volume, is shown in the following table. In calculating the latter the molecular weight of 
872 IAUNCELOT $W$. ANDREWS AND HENRY MAX GOETTSCH.

starch is arbitrarily assumed as that of the molecule $\left(\mathrm{C}_{6} \mathrm{H}_{10} \mathrm{O}_{5}\right)_{0}=972.5$.

\section{TABLE IV.}

$\begin{array}{ccccc}\begin{array}{c}\text { Solution } \\ \text { No. }\end{array} & \begin{array}{c}\text { Starch, grams } \\ \text { perliter. }\end{array} & \begin{array}{c}\text { Iodine, grams } \\ \text { per liter. }\end{array} & \begin{array}{c}\text { Molecular volume } \\ \text { of starch. }\end{array} & \begin{array}{c}\text { Molecular volume } \\ \text { of iodine. }\end{array} \\ \text { I } & 19.225 & 2.562 & 50.69 & 99.02 \\ 2 & 14.42 & 1.922 & 67.58 & 132.03 \\ 3 & 9.61 & 1.281 & 101.38 & 198.04 \\ 4 & 7.21 & 0.961 & 135.16 & 264.06 \\ 5 & 4.806 & 0.641 & 202.76 & 396.08 \\ 6 & 2.403 & 0.320 & 405.52 & 792.16\end{array}$

It is obvious that these solutions prepared by the action of iodine on starch at about $100^{\circ}$ are entirely different in composition from those previously described, which were made at about $20^{\circ}$ from dissolved starch. The former correspond very closely with the formula $\left(\mathrm{C}_{6} \mathrm{H}_{10} \mathrm{O}_{5}\right)_{12} . \mathrm{I}_{2}$, whereas we have seen that the latter possesses a composition nearly agreeing with the formula $\left(\mathrm{C}_{6} \mathrm{H}_{10} \mathrm{O}_{5}\right)_{12} . \mathrm{I}$.

The solutions were shaken with chloroform repeatedly, exactly as described on a previous page. Unfortunately the temperatures were not kept constant during the extractions, and the figures show that the results were influenced by this circumstance to a much greater degree than was anticipated. It is nevertheless thought worth while to record the data obtained, since they demonstrate that in spite of the difference in percentage of iodine in the starch iodicle as prepared cold and hot respectively, yet the behavior of both kinds toward an immiscible solvent is similar.

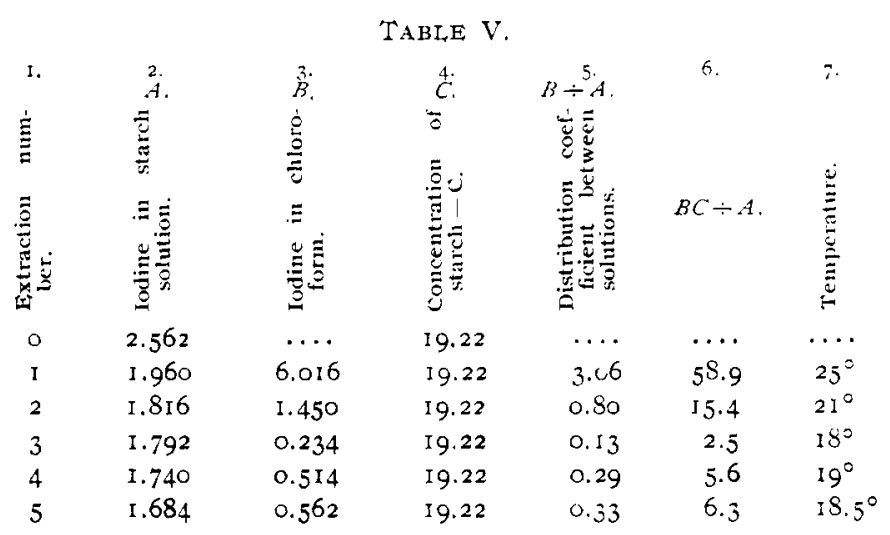


STARCH IODIDE.

\begin{tabular}{|c|c|c|c|c|c|c|}
\hline I. & 2. & 3. & 4. & 5. & 6. & 7. \\
\hline & A. & $B$ & C. & $B \div A$ & & \\
\hline 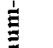 & $\bar{\Xi}$ & $\underline{b}$ & $\ddot{0}$ & 㟧 & & \\
\hline & $\bar{v}$ & E & ن. & $=\frac{5}{0}$ & & $\dot{\varphi}$ \\
\hline : & 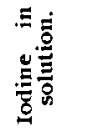 & 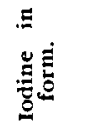 & 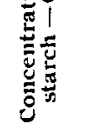 & 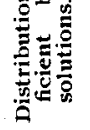 & $B C+A$ & 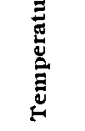 \\
\hline 0 & 1.922 & $\ldots$ & I 4.42 & $\ldots$ & $\ldots$ & $\ldots$ \\
\hline I & I. 414 & 5.068 & 14.42 & 3.58 & 51.6 & $25^{\circ}$ \\
\hline 2 & I. 308 & 1.068 & 14.42 & 0.82 & I I. 7 & $21^{\circ}$ \\
\hline 3 & I. 290 & 0.172 & 14.42 & 0.13 & 1.9 & $18^{\circ}$ \\
\hline 4 & I. 244 & 0.460 & 14.42 & 0.37 & 5.4 & $19^{\circ}$ \\
\hline 5 & 1.212 & 0.328 & I 4.42 & 0.27 & 3.9 & $18.5^{\circ}$ \\
\hline 0 & $\mathrm{I} .28 \mathrm{I}$ & $\ldots$ & $9.6 \mathrm{r}$ & $\ldots$ & ... & ... \\
\hline I & 0.904 & 3.782 & $9.6 \mathrm{I}$ & 4.45 & 42.8 & $25^{\circ}$ \\
\hline 2 & 0.824 & 0.796 & $9.6 \mathrm{I}$ & 0.96 & 9.2 & $21^{\circ}$ \\
\hline 3 & 0.804 & 0. 196 & $9.6 \mathrm{I}$ & 0.24 & 2.3 & $18^{\circ}$ \\
\hline 4 & $0.77^{8}$ & 0.262 & $9.6 \mathrm{I}$ & 0.34 & $3 \cdot 3$ & $19^{\circ}$ \\
\hline 5 & 0.756 & 0.220 & $9.6 \mathrm{I}$ & 0.29 & 2.8 & $18.5^{\circ}$ \\
\hline o & $0.96 \mathrm{I}$ & $\ldots$ & 7.206 & $\ldots$ & $\ldots$ & $\cdots$ \\
\hline I & $0.65^{\circ}$ & 3.102 & 7.206 & 4.77 & 34.4 & $25^{\circ}$ \\
\hline 2 & 0.594 & 0.562 & 7.206 & 0.95 & 6.7 & $2 I^{\circ}$ \\
\hline 3 & $0.5^{82}$ & 0.118 & 7.206 & 0.20 & 1.4 & $18^{\circ}$ \\
\hline 4 & 0.554 & 0.284 & 7.206 & $0.5^{r}$ & 3.7 & $19^{\circ}$ \\
\hline 5 & 0.546 & 0.090 & 7.206 & 0.16 & 1.2 & I $8.5^{\circ}$ \\
\hline o & $0.64 I$ & $\ldots$ & 4.805 & $\ldots$ & $\ldots$ & $\ldots$ \\
\hline I & 0.416 & 2.240 & 4.805 & $5 \cdot 3^{8}$ & 25.9 & $25^{\circ}$ \\
\hline 2 & $0.37^{\circ}$ & 0.460 & 4.805 & I. 24 & 6.0 & $2 I^{\circ}$ \\
\hline 3 & $0.35^{8}$ & O. I 20 & 4.805 & 0.33 & I. 6 & $18^{\circ}$ \\
\hline 4 & 0.336 & 0.222 & 4.805 & 0.66 & 3.2 & $19^{\circ}$ \\
\hline 5 & 0.322 & 0.142 & 4.805 & 0.44 & $2 . I$ & I $8.5^{\circ}$ \\
\hline 0 & 0.320 & $\cdots$ & 2.403 & $\ldots$ & $\ldots$ & $\ldots$ \\
\hline I & 0.188 & 1.32 & 2.403 & 7.02 & 16.8 & $25^{\circ}$ \\
\hline 2 & 0.160 & 0.286 & 2.403 & I.79 & $4 \cdot 3$ & $25^{\circ}$ \\
\hline 3 & 0.152 & $0.07^{8}$ & 2.403 & $0.5^{I}$ & I. 2 & $18^{\circ}$ \\
\hline 4 & o. 136 & 0.152 & 2.403 & 1.12 & 2.7 & $19^{\circ}$ \\
\hline 5 & 0.132 & $0.05^{\circ}$ & 2.403 & $0.3^{8}$ & 0.9 & $18.5^{\circ}$ \\
\hline
\end{tabular}

Series 5.-More significant than the last experiments and freer from sources of error, are a number of determinations of the vapor-tension of the iodine in solutions of starch iodide, carried out after the method described by one of us in the preceding paper.

A solution was used for this purpose which contained I9.224 grams of dry starch and I.485 grams of "free" iodine per liter, and which was prepared after the method already described by 


\section{LAUNCELOT W. ANDREWS AND HENRY MAX GOETTSCH.}

heating the constituents together to $99^{\circ}$. The liquid was placed in a gas-washing apparatus, immersed in a tank of water, and a slow current of dried air was aspirated through it and then through a second similar apparatus identically charged. The object of the second vessel is to serve as control, its constancy of weight demonstrating that the current of air was slow enough to be fully saturated with the vapors of both water and iodine at the prevailing tension. In practice, small losses in the weight of this vessel were disregarded, a special experiment having shown that the ratio between iodine and water evaporated is the same when the air is nearly (95 per cent.) saturated as when it is fully so.

The total amount of water plus iodine evaporated during each period is given by the loss in weight of the bulb. The amount of iodine evaporated is determined by titration of the solution by $\mathrm{N} /$ Ioo thiosulphate at the close of each period of evaporation, and the water estimated by difference. The data of one such series of measurements are reproduced in Table VI. The tension in millimeters $(s)$ of the iodine is found by the formula

$$
s=0.07 \mathrm{I} \times \frac{w S}{W} \text { (see preceding paper), in which }
$$
and

$S=$ the tension of water-vapor at the prevailing temperature,

$w=$ the weight of water evaporated, and

$W=$ the weight of iodine evaporated.

To secure greater accuracy, for each titration about $5 \mathrm{cc}$. of the solution were withdrawn and its weight determined. The iodine concentrations are accordingly given in milligrams per gram.

The minuteness of the tension of the iodine (less than $0.0 \mathrm{Imm}$.) in solutions where the iodine forms 5 per cent. of the weight of the starch present is remarkable. To obtain correspondingly low tensions of iodine in solutions of potassium iodide, the amount of iodine must be reduced relatively to a much greater degree, but the general character of the curve is very similar. We have not as yet been able to calculate any satisfactory dissociation constant from the data. All the results obtained, both by the vaportension method and by the chloroform method, show the complexity of the phenomena involved, and lead to the hypothesis that the iodine in "starch iodide" solutions exists in two forms of union at least, a small portion of it being much more readily removed than the rest. 
STARCH IODIDE.

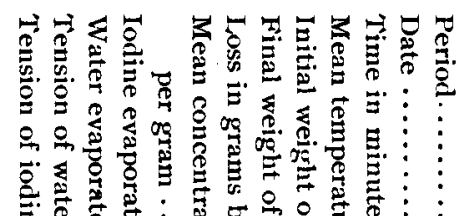

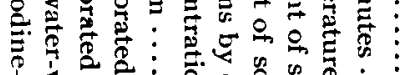

裹亭

5)

$\frac{2}{2}$

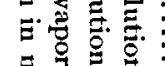

焉

宓

苟

$\geqslant$ ह

$\stackrel{\rho}{\mathrm{s}+}$

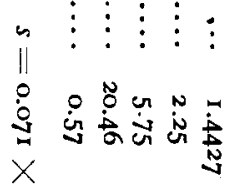

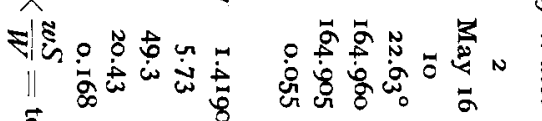

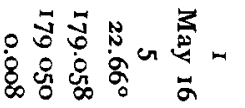

2

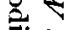

: 


\section{LAUNCELOT W. ANDREWS AND HENRY MAX GOETTSCH.}

The differences between the composition of the starch iodicleprepared cold and that made by the aid of heat, invite a further examination of the action of high temperatures on this substance. The authorities disagree radically as to the phenomena resulting from the action of heat on solutions of this kind, some maintaining while others deny the permanent decolorization by heat when volatilization of iodine is prevented. We accordingly undertook an investigation of this matter.

Series 6.-A somewhat dilute solution of starch iodide sealed up in a tube of Jena glass and heated to $100^{\circ}$ becomes colorless if very dilute, or straw color if less so. The color returns in its original intensity (colorimetric determination) if the tube is small and is rapidly heated to the required temperature and quickly cooled. But if the heating is continued, the color returns on cooling with ever feebler intensity, and at last fails to return at all. Seventy cc. of a solution of starch iodide (prepared like those referred to in Table V) were sealed in a Jena glass tube and heated in a steam-bath for several days, eight to ten hours each day. The solution did not lose its blue color at first (being too concentrated to do so) but the upper part of the tube showed the violet vapor of iodine. After four days the violet vapor had disappeared and the solution had become green. After heating fifty hours, the solution had become light yellow and the operation was discontinued. No pressure was apparent on opening the tube.

The solution was filtered from an insignificant greenish sediment. It was pale yellow, and gave the following reactions: Shaken with chloroform the latter becomes violet and the solution colorless. Starch paste turns it blue. Hence, free iodine is present and $\operatorname{starch}^{1}$ is absent. Iodine dissolved very copiously in it, giving a dark brown solution. Methyl orange indicated a strongly acid reaction. Potassium nitrite set free a considerable quantity of iodine; hence, hydriodic acid is present. Mercurous nitrate gave a greenish precipitate of mercurous iodide. The solution reduced Fehling's solution, and on boiling with phenylhydrazine and acetic acid gave the crystalline precipitate characteristic of glucose.

For the purpose of quantitative study of these products, another

1 Consequently the statement of Stocks (Chem. News, $\mathbf{5 7}, 18_{3}$ ), that scarch is unaltered on heating with iodine in a sealed tube, is incorrect. 
portion of the material was sealed up and heated as before. The changes of color observed are noted below.

After heating five hours the color while hot was dark blue.

After heating fifteen hours the color while hot was black.

After heating twenty-five hours the color while hot was very dark green.

After heating thirty-five hours the color while hot was paler green.

After heating forty-five hours the color while hot was applegreen.

After heating fifty-five hours the color while hot and cold was yellow.

After heating sixty-five hours the color while hot and cold was colorless.

The product gave the same reactions as those described for the portion heated fifty hours, excepting the reactions of free iodine. Five cc. of the solution, titrated with $\mathrm{N} /$ Ioo potassium hydroxide and methyl orange, required $1.22 \mathrm{cc}$., which corresponds to $\mathrm{I} .55$ mg. of hydriodic acid. As the solution had previously been ascertained, by titration with thiosulphate, to contain in $5 \mathrm{cc}$. $12.8 \mathrm{I} \mathrm{mg}$. of iodine, it follows that I2.I2 per cent. of the iodine originally present had, by continued heating, been converted into hydriodic acid.

Another portion of $5 \mathrm{cc}$. was neutralized with calcium carbonate and titrated with standard silver solution, using potassium chromate as indicator. We found thus in the $5 \mathrm{cc}$., $13.3 \mathrm{I} \mathrm{mg}$. of iodine. It follows that the greater part of the iodine is present in the form of a colorless organic iodide which gives up the whole of its iodine readily in the cold to a silver nitrate solution. The discrepancy between the $13.3 \mathrm{I} \mathrm{mg}$. found by the silver solution and the $12.8 \mathrm{I} \mathrm{mg}$. found by thiosulphate, is not due to experimental error, but is explained by the fact that solutions of starch iodide which have been made by heating for the normal period of about two hours contain a certain amount of the colorless organic iodide -an amount which one of us has found to average between three and four per cent. of the total iodine present. The organic iodide can not be removed even in traces from the solution which has been heated sixty-five hours, by shaking it with chloroform subsequent to neutralization. The existence of a colorless organis 
iodide has been assumed, but not demonstrated, by Bondonneau, ${ }^{1}$ by Duroy, ${ }^{2}$ and by Guichard, ${ }^{3}$ although the last mentioned certainly came very near a demonstration by showing that starch iodide solutions, which have lost all color by evaporation of iodine, may be turned blue again by adding nitric acid, even when the hyclriodic acid has (presumably) been removed by desiccation.

An important factor in the clecolorization of starch iodicle by prolonged heating is cloubtless to be found in the saccharification of the starch by the hydriorlic acid formed. That this is, however, not an essential factor was clemonstrated by heating starch iodide with a small quantity of calcium carbonate in a glass tube. The heating had to be continued i 10 hours to produce complete decolorization, whereas without the carbonate, under otherwise identical conditions, sixty-five hours sufficed. It starch iodicle solutions are boiled in the open air until fully colorless, the restiting solution contains starch, hydriodic acid, colorless organic iodide, and glucose. Its color may be restored by addition of iodine or of iodate or of nitrous acid, etc.

While we are conscious that the question as to whether the substance called starch iodide is a compound or a solution of iodine in starch is still unsettled, we still believe that the observations recorded in this paper are more reconcilable with the former view than with the latter. If the biue color is due to the formation of a mere solution of iodine in starch, it is difficult to understand why iodine can not color dry starch blue, but the fact is that perfectly dry iodine imparts to perfectly dry starch a brownish color which becomes blue on contact with a trace of water. The presence of an organic solvent does not alter this phenomenon.

If the blue substance formed in presence of water is a mere solution of iodine in starch, what, we would like to ask, is the brown substance formed when iodine dissolves in starch in absence of water?

Potassium iodide, as is well known, in large excess imparts a brownish violet color to starch iodide solutions, dilution with water restoring the blue. As Mylius has observed, iodic acid changes the blue of starch iodide to brown, a fact which he uses to support the view that iodides must be present as an essential

1 Bull. Soc. Chim., 28, 452 (1877).

${ }^{2}$ Compt. rend., $\mathbf{5 1}, 1031$ (1860); see also Chem. News, $\mathbf{3}, 16$.

${ }^{3}$ Bull. Soc. Chim., 5, it5 (1853). 
part of the starch-blue. On this theory the change of color is simply caused by the removal of all iodide by the iodic acid. We have, however, found that if to the brown solution so formed, sodium or potassium bicarbonate or other weakly alkaline substances be added, the blue is immediately restored. This is inexplicable on the theory alluded to, but is easily understood if the possibility of iodine acting as a base is borne in mind, a possibility which has of late been shown by other authors ${ }^{1}$ to be a probability. This involves the supposition that the iodic acid removes the iodine from the starch iodide in the form of iodine iodate, ${ }^{2}$ and that when a stronger base is added, the weaker one (iodine) is displaced and placed at the disposition of the starch once more.

\section{SUMMARY.}

Clear starch solutions made at a temperature of about $\mathrm{I}_{5} 0^{\circ}$ take up in the cold an amount of iodine corresponding to the formula $\left(\mathrm{C}_{6} \mathrm{H}_{10} \mathrm{O}_{5}\right)_{12} \mathrm{I}$. Starch heated with excess of iodine to $100^{\circ}$ for a short time takes up an amount of iodine corresponding to the formula $\left(\mathrm{C}_{6} \mathrm{H}_{10} \mathrm{O}_{5}\right)_{12} \mathrm{I}_{2}$. Starch and iodine heated to $100^{\circ}$ for a longer time give ultimately a colorless solution which contains most of the iodine in the form of an organic iodide, a smaller part of it in the form of hydriodic acid, and which also contains glucose but no starch.

Solutions of starch iodide on shaking with chloroform yield, at first, considerable amounts of iodine to the latter but after removal of the first portion, give up iodine very slowly, showing no indication of a distribution coefficient of iodine between starch and chloroform as might be expected if the iodine were merely dissolved in the starch. The vapor-tension of iodine in solutions of starch iodide was determined by a new method, and was found to be extremely minute after the removal of the first portion of the iodine.

It is held that the substance known as starch iodide is to be

1 Compare also for a similar assumption applied to chlorine, Noyes and Iyon : This Journal, 23, 463 .

2 The process imagined may be represented by ioric equations as follows, the symbol Ss standing for the starch complex. :

$$
\begin{gathered}
\mathrm{SSI}+\overrightarrow{\mathrm{H}}+\overline{\mathrm{IO}} \mathrm{O}_{3}=\mathrm{SSH}+\overrightarrow{\mathrm{I}}+\overline{\mathrm{IO}} \\
\mathrm{H}_{2} \mathrm{O}+\overrightarrow{+}+\overline{\mathrm{IO}}_{3}=\mathrm{IOH}+\overrightarrow{\mathrm{H}}+\overline{\mathrm{IO}} \mathrm{O}_{3} \\
\overline{\mathrm{SSH}}+\mathrm{IO}+2+\frac{+}{+}+\overline{\mathrm{IO}}_{3}=\mathrm{SSI}+2 \overrightarrow{\mathrm{K}}+\overline{\mathrm{IO}}_{3}+\mathrm{O} \overline{\mathrm{H}}
\end{gathered}
$$


looked upon as a dissociable additive compound of iodine with starch molecules, more or less depolymerized, according to the temperature employed, and subject therefore to variation in the ratio of starch to iodine. These views are supported by the following considerations:

I. Starch and iodine can not unite to produce the blue substance in the absence of water, a phenomenon frequently characteristic of chemical combination but not of solution in organic solvents.

2. The temporary decolorization of the blue solution by heat when loss of iodine is prevented is much better explained as a phenomenon of dissociation than of solution.

3. The fact that in the system, starch, water, chloroform, a rise of temperature has a very powerful effect in causing iodine to pass from the starch to the chloroform, indicates that the union of starch and iodine is exothermic, and agrees well with the hypothesis of a dissociable compound.

4. The fact that the amount of iodine taken up by the starch under different conditions, as to the temperature to which the starch is subjected either before or after iodine is added is naturally explained by the view that the molecule undergoes gradual depolymerization by steps, giving rise to two, or a series. of starch iodides of different composition. This also explains why no dissociation constant can be deduced.

5. The remarkably low vapor tensions of the iodine in these solutions, while quite natural if the iodine is combined, are exceptional and difficult to understand on any other basis.

The experimental part of this investigation was completed as here presented, two years ago, but publication was delayed by the temporary accidental loss of the records.

The authorities consulted (part of them it is proper to state by abstracts) are given in the following list, which is as complete a bibliography of the literature of starch iodide as we have been able to compile with the library facilities available.

\section{BIBLIOGRAPHY.}

(Figures given in parentheses are series numbers, those in heavy type volume numbers.)

Baudrimont, E.: Compt. rend., 51, 825 (1860).

Béchamp, A.: J. pharm. Chim., [3], 27, 406; 28, 303 (1855).

Blondlot: Ann. chim. phys., [3], 43, 225 (1855).

Bondonneau, L.: Compt. rend., 85,671, 673 (1877) ; Bull. Soc. Chim.. $[2], 28,452(1877)$.

Brukner, B.: Monatsh. Chem, 4, 889, 906 ( 1883 ).

Deventer, Ch.M. van : Chem. Centrbl., (1888), p. 424. 
Duclaux, E.: Compt. rend., 74, 533 (1872); Ann. chim. phys., [4], 25, 264 ( 1872 ).

Duroy : Compt. rend., 5I, 103 I (1860).

Fresenius, R.: Pogg. Ann., r02, 184 (1857) ; Ztschr. anal. Chem., I, 84 ( I862).

Fritzsche: Watt's Dicticnary, Vol. IV, p. 510 ; Ann. Chem. (Liebig), I2, 287 ( I 834 ).

Geubel : Jahresber. pr. Pharm., 24, 337 (1852).

Girard, Aimé : Ann. chim. phys., [6], 12, 275 (1887).

Goppelsröder, Fr.: Pogg. Ann., Iog, 57 (1863).

Guichard: Chem. News, 18, 6 (abst.), (1868).

Guichard, P.: Bull. Soc. Chim., [I], 5, I 55, 278 (1863).

Harz, C.O: "Alkohol"'(1898), p. I 16; Chem.Centrbl., I, Ior8 (abst.), (1898).

Kemper: Arch.d. Pharm., I62, 253 (1862).

Küster, F. W.: Ann. Chem. (Liebig), 283, 360 (1895); Ber. d. chem. Ges , ( 1895 ), p. 753.

Laissaigne : Jour. Chim. Med. [3], 7, 180 (1851).

Lownes, C.: Ztschr. anal. Chem., (1894), p. 409.

Magnes-Lahens, M.: J. pharm. Chim., [3], 19, 243 (1849); Ibid., [3], 2I, $I_{3}\left(\mathrm{I}_{5} \mathrm{I}\right)$.

Meineke, C.: Chem. Ztg., 18, I57 (1894).

Mylius, F.: Ber. d. chem. Ges., (1887), p. $688 ;$ Ibid., (I895), p. 388.

Nägeli, C. W.: Institut., (1863), p. 263.

Payen, A.: Compt. rend., 6r, 512 (1865).

Pellet, H.: Bull. Soc. Chim., 27, 147 (1877).

Personne, J.: Bull. Soc. Chim., I, 455 (1860); J.pharm. Chim., [3], 39, 49 ( I 86I).

Pickering, S. P. U.: Chem. Ne'ws, 42, 3 I I (1880).

Pisani, Félix: Compt. rend., 43, IIIS (1856); J. prakt. Chem., 70, 382 .

Pohl, J. J.: J. prakt. Chem., 83, 38 (186I).

Potilitzin, A. L.: Ber. d. Chem. Ges., (1880), p. 2400; Jahresber., ( 1880 ), P. 246.

Puchot, Ed.: Compt. rend., 83, 225 (1876).

Roberts, C. F.: Am.J. Sci., 147, 422 (J894).

Rouvier, E. G.: Compt. rend., II4, 749, I 366, 128 (I892); Ibid., II 7, 28I , 46r (I893); Ibid., 118, 743 (1894); Ibid.. 124, 565 (1897).

Schär, Ed.: Ph. Centralhalle, 37, $540(1895)$.

Schoenbein, C. F.: J. prakt. Chem., 84, 395 (1861); Chem. Centrbl., (I 862 ), p. 239.

Seput: J.pharm. Chem., [3], 2I, 202 (185r).

Seyfert, F.: Ztschr, angew. Chem., 15, 126 (1888).

Sonstadt, E.: Chem. News, 25, 248 ( 1872 ).

Soubeiran, J. L.: J. pharm. Chem, , [3], 21, 329 (1852).

Stocks, H. B.: Chem. Newe, 56, 212 (1887); Ibid., 57, 183 (1888).

Tomlinson, C.: Phil. Mag., [5], 20, I68 ( 1885 ).

Tóth, J.: Chem. Ztg., 15, I523, I583 (189I).

Van Deventer : See Deventer, Ch.M. van.

Vogel, Alfred : N. Rep. Pharm., 22, 349 (1873) ; Ibid., 25, 565 (1875). 